\title{
Examination of the cylindrical worm profile
}

\author{
Tadeusz Nieszporek ${ }^{1}$, and Piotr Boral ${ }^{1, *}$ \\ ${ }^{1}$ Czestochowa University of Technology, Institute of Mechanical Technologies, Al. Armii Krajowej \\ 21, 42-201 Czestochowa, Poland
}

\begin{abstract}
The article has presented a special case of machining a cylindrical worm with a fixed and variable pitch. The worm is machined with a cylindrical finger-type mill positioned perpendicularly to the worm axis. The axial profile and axial profile angle of the worm have been calculated and measured. The effect of the offset on the accuracy of the worm axial profile has been examined.
\end{abstract}

\section{Introduction}

Fixed-pitch cylindrical worms are used chiefly in worm gears. Fixed and variable-pitch cylindrical worms are used also in extruding presses and feeders in plastic processing and in the food industry. The shaping of fixed-pitch cylindrical helicoids has been extensively covered in the literature $[1,2]$, while the technology of variable-pitch helical surfaces is not addressed. The helical surfaces of worms are most commonly machined by the hobbing method using rotary tools $[1,3]$.

Cone-derivative helical surfaces are predominant, which are formed using a tool with the rectilinear axial profile of the tool action surface $[4,5]$. The tool profile angle is, in a general case, different from zero, and the cylindrical finger-type mill is a special case of the helical surface forming rotary tool. The equations of the cone-derivative cylindrical helicoid, in a general form, consider disc, ring, finger and cup-type tools [6], but they do not include the cylindrical finger-type mill due to the surd in the envelope condition [7].

\section{Worm surface}

In a general case, the following worm helical surface geometrical parameters, among others, are given - Figure 1: $d_{a}$ - outer diameter, $d_{f}$ - cut bottom diameter, $L$ - length, $h_{1}$ pitch at the beginning, $h_{2}$ - pitch at the end, $s_{1}$ - offset at the beginning, $s_{2}$ - offset at the end. A linear variation in pitch and offset over the worm length is assumed.

In the case of cutting the helical surface using a cylindrical finger mill with a rectilinear tool action surface profile, the profile angle will be equal to pi/2 - Figure 2 . In the general case of forming a cone-derivative helical surface with a cylindrical finger mill, a surd will occur in the envelope equation [7]. Therefore, this machining method has been treated as a

\footnotetext{
*Corresponding author: piotrek@itm.pcz.pl
} 
special case of helical surface forming. This is, however, a worm machining technology that is used in practice.

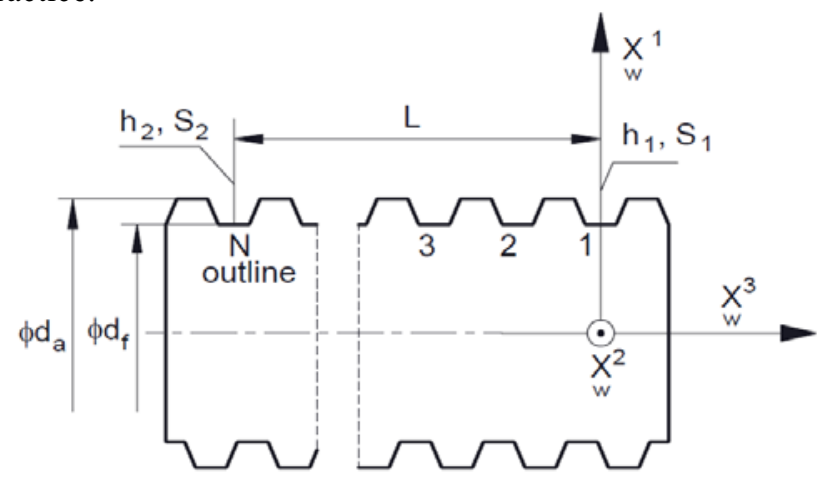

Fig. 1. Worm geometrical parameters.

This helical surface machining method can also be used for initial rough cutting of a worm with an arbitrary profile. This is so because the tool is geometrically simple and cheap - Figure 2.

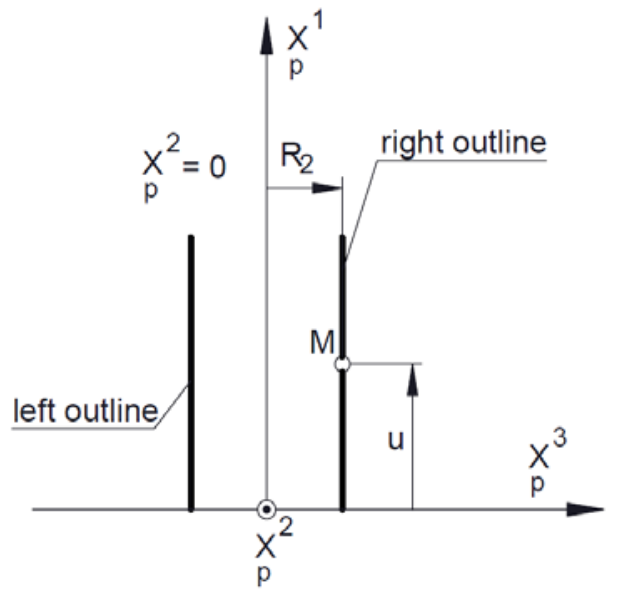

Fig. 2. The axial profile of the cylindrical finger mill action surface.

Comparison of the mill profile in the coordinate system $\{p\}$ is as follows:

$$
u \in\left\langle u_{\min }, u_{\max }\right\rangle \rightarrow \underset{\mathbf{p}}{\mathbf{x}}(u)=\left[\begin{array}{lll}
u, & 0, & R_{2}
\end{array}\right]^{T} \in \mathrm{E}
$$

where: $u$ - tool axial profile parameter; $R_{2}$ - mill radius; $\mathbf{x}$ - subscript $*$ identifies the coordinate system. 


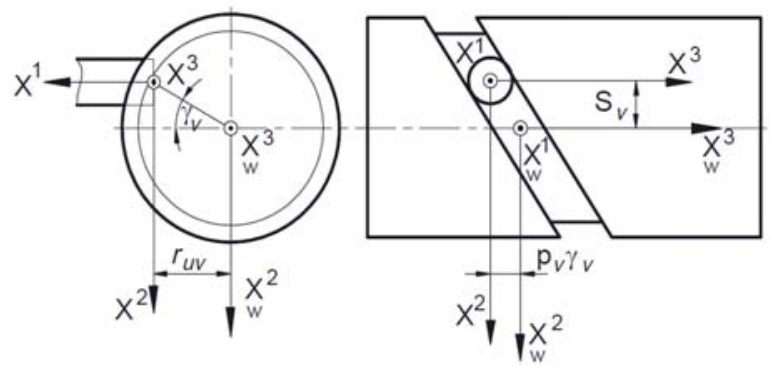

Fig. 3. Tool and worm relative positioning.

The relative positioning of the tool in the worm's system can be described with the equation - Figure 3

$$
\mathbf{x}=[1, \quad \varphi]_{p}^{\mathbf{x}}+\left[\begin{array}{lll}
r_{u v}, & -s_{v}, & -p_{v} \gamma_{v}
\end{array}\right]^{T}
$$

where: $\varphi$ - tool action surface parameter; $r_{u v}$ - mill distance from the axial plane $X^{2} X^{3}$ of the helicoid; $s_{v}$ - mill offset over the worm length; $p_{v}$ - helical surface parameter; $\gamma_{v}$ angle between the plane $X^{1} X^{3}$ of the helicoid and the radius vector of the point on the tool axis.

The pitch and the offset are variable over the worm length - Figure 1. It is assumed that the worm length is the multiple of the average pitch, or

$$
o=\frac{4 \pi L}{h_{1}+h_{2}}
$$

where: $o$ - the number of relative tool and worm revolutions over the worm length.

So, the helical surface parameter is equal to

$$
p_{v}=\frac{1}{2 \pi}\left(h_{1}+a_{h} v\right) \quad a_{h}=\frac{h_{2}-h_{1}}{o}
$$

where: $a_{h}$ - coefficient of helical surface parameter variation over the worm length.

In a similar manner - Figure 3, the parameters of tool positioning in the worm's system are described

$$
\begin{array}{ll}
s_{v}=\frac{1}{2 \pi}\left(s_{1}+a_{s} v\right) & a_{s}=\frac{s_{2}-s_{1}}{o} \\
r_{u v}=\sqrt{\left(\frac{d_{f}}{2}\right)^{2}-\left(s_{v}\right)^{2}} & \gamma_{v}=\operatorname{arctg} \frac{s_{v}}{r_{u v}}
\end{array}
$$

where: $a_{s}$ - coefficient of offset variation over the worm length. 


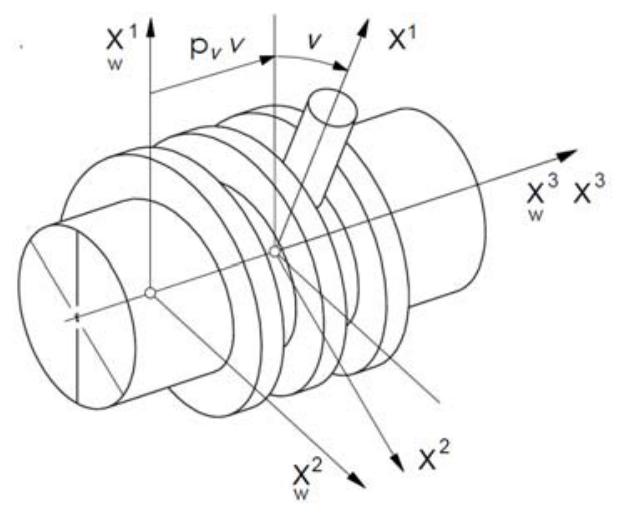

Fig. 4. Relative worm and mill motion.

If we consider the relative motion of the tool and the worm in the machining process Figure 4, then the family of tool action surfaces can be written with the following equation

$$
\underset{w}{\mathbf{x}}=\left[\begin{array}{ll}
3, & -v
\end{array}\right] \mathbf{x}+\left[\begin{array}{lll}
0, & 0, & \pm p_{v} v
\end{array}\right]^{T}
$$

where: \pm - for the right-hand and left-hand worm, respectively.

In order to describe the worm surface, the envelope condition should be included in Equation (7), which can be generally written in the form of the triple product of three vectors $[3,5]$

$$
f=\frac{\partial \mathbf{x}}{\partial u} \frac{\partial \mathbf{x}}{\partial \varphi} \frac{\partial \mathbf{x}}{\partial v}=0
$$

After transformations, this equation has the following form

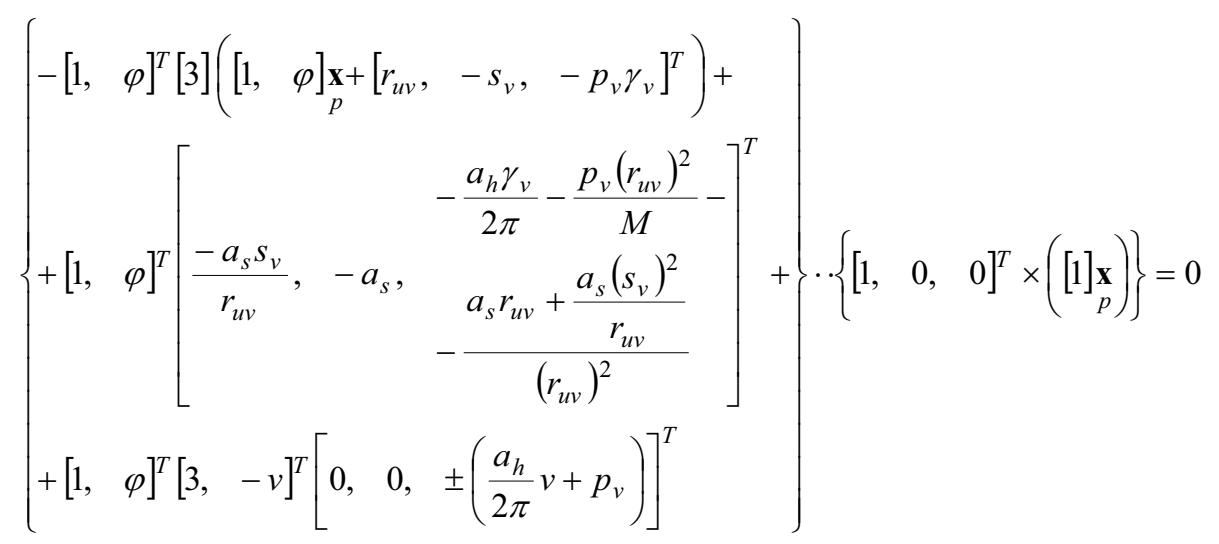

where the following denotation is adopted

$$
M=\left(r_{u v}\right)^{2}+\left(s_{v}\right)^{2}
$$

The profile angle was defined by determining the angle of the straight line passing through the extreme points of the profile. 


\section{Calculation results}

The axial profile of a worm machined with a cylindrical finger mill with a rectilinear tool action surface axial profile is non-rectilinear, which results from the specificity of hobbing. In the case of a worm with a fixed pitch and a fixed offset, the worm profile is constant Figure 5a. For a worm with a variable pitch and a fixed offset, the worm profile varies over the worm length - Figure $5 b$.
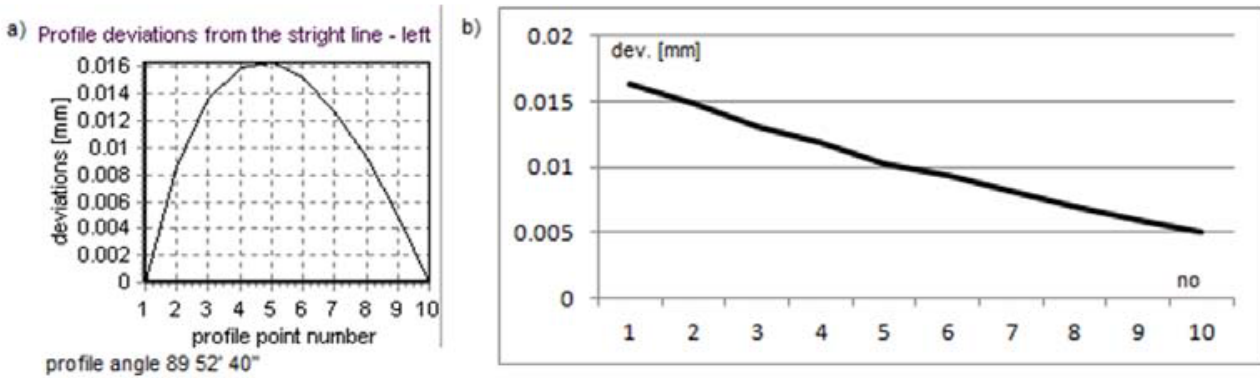

Fig. 5. A worm $L=150 \mathrm{~mm}, d_{f}=28 \mathrm{~mm}, s_{1}=s_{2}=0 \mathrm{~mm}$ : a) axial profile $\left(h_{2}=h_{1}\right)$, b) maximum deviations of successive axial profiles from the straight line $\left(h_{1}=10 \mathrm{~mm}, h_{2}=20 \mathrm{~mm}\right)$.

A very great effect on the worm profile is exerted by the offset - Figure 6, whereas, for machining the two sides of the worm cut, the offset should be equal in value and opposite in sign for the profiles for the both cut sides be the same. The relationship between the worm axial profile deviation from the straight line and the offset is linear - Figure 6.

So, in the case of variable-pitch worms, the worm profile can be influenced by changing the offset - Table 1. A continuous change in pitch and offset can be accomplished on a $\mathrm{CNC}$ machine tool. By changing the offset, worm axial profile errors can be reduced, and also profile angle errors can be diminished.

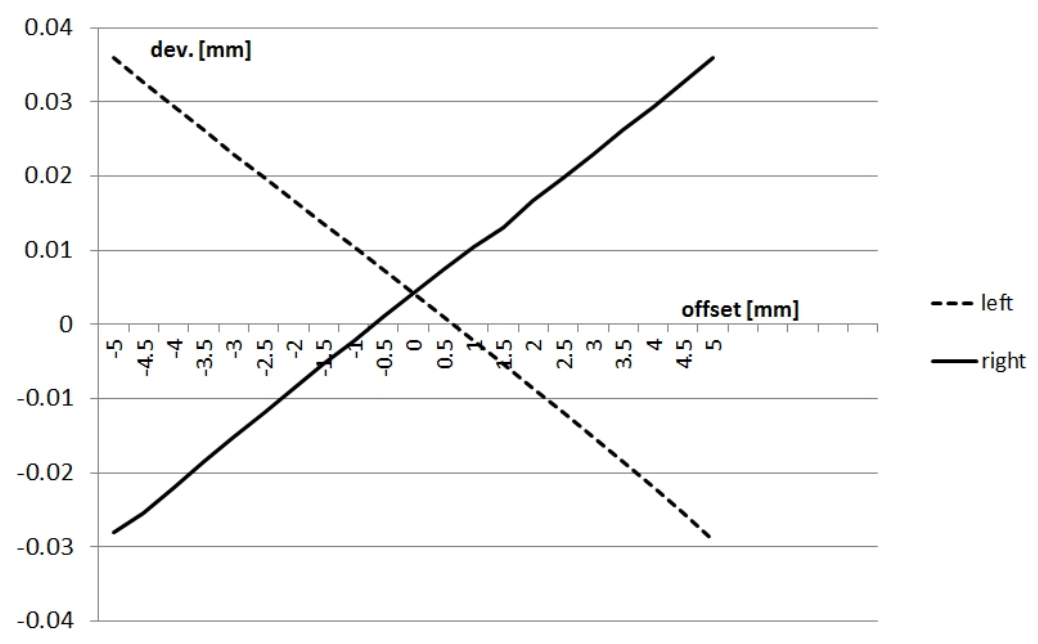

Fig. 6. Deviations of the worm axial profile from the straight line as a function of the offset $L=150 \mathrm{~mm}, d_{f}=28 \mathrm{~mm}\left(h_{2}=h_{1}=10 \mathrm{~mm}\right)$. 
Table 1. Offset the impact on the outline of a worm: $L=150 \mathrm{~mm}, d_{f}=28 \mathrm{~mm}, h_{1}=10 \mathrm{~mm}$,

$h_{2}=20 \mathrm{~mm}$.

\begin{tabular}{|c|c|c|c|c|c|c|}
\hline $\begin{array}{c}\text { Profile } \\
\text { No. }\end{array}$ & $\begin{array}{l}\text { Offset } \\
{[\mathrm{mm}]}\end{array}$ & $\begin{array}{c}\text { Deviation } \\
\text { [mm] }\end{array}$ & Angle & $\begin{array}{l}\text { Offset } \\
{[\mathrm{mm}]}\end{array}$ & $\begin{array}{c}\text { Deviation } \\
{[\mathrm{mm}]}\end{array}$ & Angle \\
\hline 1 & \multirow{11}{*}{0.0} & 0.0163 & 89 31'25', & 1.25 & 0.00102 & ' 8948 '487' \\
\hline 2 & & 0.0148 & 89 34'01' & 1.15 & 0.00135 & 89 50’31' \\
\hline 3 & & 0.0133 & 89 36'39' & 1.00 & 0.00139 & 89 54'07' \\
\hline 4 & & 0.0118 & 89 39'07'י & 0.95 & 0.00191 & 89 54'39'” \\
\hline 5 & & 0.0105 & 89 41'27' & 0.86 & 0.00204 & 89 56'09'” \\
\hline 6 & & 0.0093 & 89 43'40' & 0.82 & 0.00169 & 89 56'20' \\
\hline 7 & & 0.0081 & $8945^{\prime} 46^{\prime \prime}$ & 0.75 & 0.00161 & 89 57'10' \\
\hline 8 & & 0.0070 & 89 47'42' & 0.70 & 0.00137 & 89 57'28' \\
\hline 9 & & 0.0060 & 89 49’30' & 0.65 & 0.00115 & 89 57'46' \\
\hline 10 & & 0.0050 & 89 51'10' & 0.62 & 0.00081 & 89 57'43'” \\
\hline 11 & & 0.0041 & 89 52'40' & 0.60 & 0.00045 & 89 57'32'” \\
\hline
\end{tabular}

\section{Conclusions}

In variable-pitch cylindrical worms, the axial profile varies over the worm length.

The effect of the offset on the worm axial profile is profound. To ensure the constancy of the profile of a variable-pitch worm, the offset needs to be variable over the worm length. With an opposite offset value for either side, the left-hand and right-hand worm cut sides must be machined separately.

The fixed-pitch cylindrical worm can be considered a special case of the variable-pitch cylindrical worm.

\section{References}

1. I. Dudas, The Theory and Practice of Worm Gear Drives (Penton Press, London, 2000)

2. F. L. Litvin, Theory of Gearing, NASA Reference Publication 1212, AVSCOM Technical Report 88-C-035, (1989)

3. F. L. Litvin, A. Fuentes, Gear Geometry and Applied Theory (Cambridge University Press, 2004)

4. F. L. Litvin, Development of Gear Technology and Theory of Gearing, NASA RP1406, (1998)

5. F. L. Litvin, C, L. Hasiao, Computerized simulation of meshing and contact of eneveloping gear tooth surfaces, Comp. Meth. in Appl. Mech. and Eng., 102, 337, (1993)

6. T. Nieszporek, The fundamentals of the theory of synthesis and analysis of approximate gearig, Series Monografie, 54, Czestochowa University of Technology, Czestochowa (1998)

7. T. Nieszporek, Konstrukcja narzędzi skrawajacych i technologia walcowych uzębień zewnętrznych, Series Monographs, 265, Czestochowa University of Technology Czestochowa, (2013) 